\title{
Publisher Correction to: The estimation and interpretation of coefficients in panel gravity models of migration
}

\author{
Michael P. Cameron ${ }^{1,2}$ (1) J Jacques Poot ${ }^{2,3}$ (i)
}

Published online: 7 January 2019

(c) The Author(s) 2018

\section{Publisher Correction to: Letters in Spatial and Resource Sciences https://doi.org/10.1007/s12076-018-00220-y}

Unfortunately, some correction requests of the author were not considered.

In several occurrences, instead of the Greek letter "delta" the Greek letter "gamma" has been typeset.

The publisher regrets this error and apologizes for the inconveniences caused.

The original publication has been updated.

Publisher's Note Springer Nature remains neutral with regard to jurisdictional claims in published maps and institutional affiliations.

The original article can be found online at https://doi.org/10.1007/s12076-018-00220-y.

$\triangle$ Jacques Poot

h.j.poot@vu.nl

1 School of Accounting, Finance and Economics, University of Waikato, Private Bag 3105, Hamilton 3240, New Zealand

2 National Institute of Demographic and Economic Analysis, University of Waikato, Private Bag 3105, Hamilton 3240, New Zealand

3 Department of Spatial Economics, Vrije Universiteit Amsterdam, De Boelelaan 1105, 1081 HV Amsterdam, The Netherlands 